\title{
A HIGH-FAT, REFINED SUGAR DIET REDUCES HIPPOCAMPAL BRAIN-DERIVED NEUROTROPHIC FACTOR, NEURONAL PLASTICITY, AND LEARNING
}

\author{
R. MOLTENI, ${ }^{a}$ R. J. BARNARD, ${ }^{a}$ Z. YING, ${ }^{a}$ C. K. ROBERTS ${ }^{a}$ and F. GÓMEZ-PINILLA ${ }^{a}, b *$ \\ ${ }^{a}$ Department of Physiological Science, University of California at Los Angeles, 621 Charles E. Young Drive, Los Angeles, \\ CA 90095, USA \\ ${ }^{\mathrm{b}}$ Division of Neurosurgery, UCLA Brain Injury Research Center, Los Angeles, CA 90095, USA
}

\begin{abstract}
We have investigated a potential mechanism by which a diet, similar in composition to the typical diet of most industrialized western societies rich in saturated fat and refined sugar (HFS), can influence brain structure and function via regulation of neurotrophins. We show that animals that learn a spatial memory task faster have more brain-derived neurotrophic factor (BDNF) mRNA and protein in the hippocampus. Two months on the HFS diet were sufficient to reduce hippocampal level of BDNF and spatial learning performance. Consequent to the action of BDNF on synaptic function, downstream effectors for the action of BDNF on synaptic plasticity were reduced proportionally to BDNF levels, in the hippocampus of rats maintained on the HFS diet between 2 and 24 months. In particular, animals maintained on the HFS diet showed a decrease in levels of: (i) synapsin I mRNA and protein (total and phosphorylated), important for neurotransmitter release; (ii) cyclic AMP-response element-binding protein (CREB) mRNA and protein (total and phosphorylated); CREB is required for various forms of memory and is under regulatory control of BDNF; (iii) growth-associated protein $43 \mathrm{mRNA}$, important for neurite outgrowth, neurotransmitter release, and learning and memory. Diet-related changes were specific for the hippocampus consequent to its role in memory formation, and did not involve neurotrophin-3, another member of the neurotrophin family.

Our results indicate that a popularly consumed diet can influence crucial aspects of neuronal and behavioral plasticity associated with the function of BDNF. (C) 2002 IBRO. Published by Elsevier Science Ltd. All rights reserved.
\end{abstract}

Key words: BDNF, diet, neuronal plasticity, cognitive function, water maze, hippocampus.

It is becoming well accepted that lifestyle plays a critical role in maintaining neural function throughout the lifespan of individuals. In particular, the diet typical of most industrialized western societies, rich in saturated fat and refined sugar (HFS) (Block et al., 1988) can contribute to cognitive decline in aging (Knopman et al., 2001) and can accelerate the course of dementia in Alzheimer's disease (Kalmijn et al., 2000, 1997). In spite of the potential impact of dietary factors on quality of life, most of the existing studies have been reduced to evaluate their effects on life expectancy (Taubes, 2001). It has been assumed that the effects of a HFS diet on neural function result primarily from cardiovascular dysfunction such as atherosclerosis (Kalmijn et al., 2000), neglecting a direct effect of diet on the brain. The possibility that a HFS diet can affect neural function would indicate that diet

*Corresponding author. Tel.: +1-310-206-9693; fax: +1-310-2069693.

E-mail address: fgomezpi@ucla.edu (F. Gómez-Pinilla).

Abbreviations: BDNF, brain-derived neurotrophic factor; CREB, cyclic AMP-response element-binding protein; ELISA, enzymelinked immunosorbent assay; GAP-43, growth-associated protein 43; GAPDH, glyceraldehyde-3-phosphate dehydrogenase; HFS, high-fat refined sugar diet; LFCC, low-fat complex carbohydrate diet; NT-3, neurotrophin-3; RT-PCR, reverse transcription-polymerase chain reaction; UNG, uracil glycosylase. can increase vulnerability to numerous neurological diseases and to aging-associated deficits. Therefore, it is important to determine how dietary factors can affect specific aspects of neuronal health and function.

Neuronal plasticity is the critical capacity to compensate for challenges, involving cellular and molecular mechanisms of synapse formation and function, neurite growth, and behavioral adaptation. Here we provide evidence that a HFS diet can decrease neuronal plasticity via regulation of brain-derived neurotrophic factor (BDNF). BDNF, a crucial mediator of neuronal vitality and function (Castrén et al., 1998), is emerging as a major player in neuronal events underlying learning and memory. For example, neural activity regulates the synthesis, secretion and action of BDNF, and activityinduced BDNF can facilitate synaptic efficacy (Poo, 2001). The expression of BDNF is increased in the hippocampus of animals that learn a spatial memory task (Kesslak et al., 1998; Mizuno et al., 2000), and animals with reduced expression of BDNF show deficits in learning and memory (Linnarsson et al., 1997).

Among the mechanisms by which BDNF affects neuronal plasticity, molecules such as synapsin I, growthassociated protein 43 (GAP-43), and cyclic AMPresponse element-binding protein (CREB) can play a central role. Synapsin I mediates BDNF modulation of neurotransmitter release by influencing synaptic vesicle 
exocytosis (Jovanovic et al., 1996, 2000), promotes axonal growth, and helps to maintain synaptic contacts (Baekelandt et al., 1994; Brock and O'Callaghan, 1987; Melloni et al., 1994). BDNF promotes synapsin I phosphorylation by activating tyrosine kinase B (TrkB) receptors at the presynaptic terminal (Jovanovic et al., 2000). GAP-43 is present in growing axon terminals and has important roles in axonal growth (Baekelandt et al., 1994), neurotransmitter release (Oestreicher et al., 1997), and learning and memory (Routtenberg et al., 2000). CREB, one of the best-characterized transcription factors in the brain, is required for various forms of memory including spatial learning (Silva et al., 1998; Tully, 1997; Yin and Tully, 1996), and appears to play a role in neuronal resistance to insult (Walton et al., 1999). Its phosphorylation at the transcription regulatory site (Finkbeiner, 2000) is under control of BDNF (Shaywitz and Greenberg, 1999).

\section{EXPERIMENTAL PROCEDURES}

\section{Animals and diets}

The effect of different periods of HFS diet was assessed in female 2 month old Fisher 344 rats (Harlan Sprague Dawley, Inc., San Diego, CA, USA), maintained at $22-24^{\circ} \mathrm{C}$ in a $12: 12 \mathrm{~h}$ light-dark cycle. We used female rats because they do not develop hypertension during the first year on a HFS diet (Roberts et al., 2000), and do not show atherosclerosis (Barnard et al., 1993). After acclimation of the animals for 1 week on standard rat chow, the rats were randomly assigned to a HFS diet or a low-fat, complex carbohydrate (LFCC) diet, for 2 months, 6 months, or 2 years, $n=5-8$ within each group. Diets containing a standard vitamin and mineral mix with all essential nutrients (Roberts et al., 2000) were provided in powder form ad libitum (Purina Mills Inc., Test Diets Inc., Richmond, IN, USA) in large bowls. The HFS diet is high in saturated and monounsaturated fat (primarily from lard plus a small amount of corn oil, $\sim 39 \%$ energy) and high in refined sugar (sucrose, $\sim 40 \%$ energy). The LFCC diet, used as a control diet, is the standard diet used in most rat vivaria, and is low in saturated fat ( $\sim 13 \%$ of energy from fat) and contains complex carbohydrate (starch, 59\% energy). Spontaneous motor activity in the cage was monitored for 5 days after 12 months on the diets using biotelemetric transmitters (Model VM-FH, Mini Mitter Co. Inc., Sunriver, OR, USA) implanted in the peritoneal cavity (Yirmiya et al., 1996). Output was monitored by a receiver (Model RA-1010) placed under each animal cage and collected by a peripheral processor (BCM100).

Animals for biochemical analyses were killed by decapitation, hippocampus and caudal cerebral cortex were rapidly dissected, frozen on dry ice and stored at $-70^{\circ} \mathrm{C}$. Rats used for immunohistochemistry were deeply anesthetized (Nembutal, $100 \mathrm{mg} / \mathrm{kg}$ i.p.) and killed by intracardial perfusion. All experiments were performed in accordance with the United States National Institutes of Health Guide for the Care and Use of Laboratory Animals and were approved by the University of California at Los Angeles, Animals Research Committee. All efforts were made to minimize animal suffering and the number of animals used.

Isolation of total RNA and real-time quantitative reverse transcription-polymerase chain reaction (RT-PCR)

Total RNA was isolated using RNA STAT-60 kit (TELTEST, Inc., Friendswood, TX, USA). The mRNAs for BDNF, synapsin, GAP-43, and CREB were measured by TaqMan real-time quantitative RT-PCR using ABI PRISM 7700
Sequence detection system (Perkin-Elmer, Applied Biosystems), and TaqMan EZ RT-PCR Core reagents (Perkin-Elmer, Branchburg, NJ, USA). This system directly detects the increase in fluorescence of a dye-labeled DNA probe specific for each factor under study plus a probe specific for the glyceraldehyde-3-phosphate dehydrogenase (GAPDH) gene used as an endogenous control. The sequences of probes, forward and reverse primers (Integrated DNA Technologies, (Coralville, IA, USA) were: BDNF: 5'-AGTCATTTGCGCACAACTTTAAAAGTCTGCATT-3', forward: 5'-GGACATATCCATGACCAGAAAGAAA-3', reverse: 5'-GCAACAAACCACAACATTATCGAG-3'; synapsin I: 5'-CATGGCACGTAATGGAGACTACCGCA-3', forward: 5'-CCGCCAGCTGCCTTC-3', reverse: 5'-TGCAGCCCAATGACCAAA-3', GAP-43: 5'-CTCATAAGGCTGCAACCAAAATTCAGGCT-3', forward: $5^{\prime}$ GATGGTGTCAAACCGGAGGAT-3', reverse: 5'-CTT-GTTATGTGTCCACGGAAGC-3' ; CREB: 5'-CATGGCAC-GTAATGGAGACTACCGCA-3' ; forward: 5'-CCGCC-AGCATGCCTTC-3', reverse: 5'-TGCAGCCCAATGACCA-AA-3'; neurotrophin-3 (NT-3): 5'-TGACCGACAAGTCC-TCAGCCATTGAC-3' ; forward: 5'-TGTGACAGTGAGAG-CCTGTGG3', reverse: 5'-TGTAACCTGGTGTCCCCGAA-3'. The RT reaction conditions were $2 \mathrm{~min}$ at $50^{\circ} \mathrm{C}$ as initial step to activate uracil glycosylase (UNG), followed by $30 \mathrm{~min}$ at $60^{\circ} \mathrm{C}$ as RT and completed by UNG deactivation at $95^{\circ} \mathrm{C}$ for $5 \mathrm{~min}$. The 40 cycles of two-step PCR conditions were $20 \mathrm{~s}$ at $94^{\circ} \mathrm{C}$ and $1 \mathrm{~min}$ at $62^{\circ} \mathrm{C}$.

\section{Protein measurements}

Hippocampal extracts were prepared in lysis buffer $(137 \mathrm{mM}$ $\mathrm{NaCl}, 20 \mathrm{mM}$ Tris- $\mathrm{HCl} \mathrm{pH}$ 8.0, $1 \%$ NP-40, 10\% glycerol, $1 \mathrm{mM}$ phenylmethylsulfonyl fluoride, $10 \mu \mathrm{g} / \mathrm{ml}$ aprotinin, $1 \mu \mathrm{g} / \mathrm{ml}$ leupeptin, $0.5 \mathrm{mM}$ sodium vanadate). Homogenates were centrifuged, supernatants collected and total protein was measured by the MicroBCA method (Pierce, Rockford, IL, USA). BDNF protein was detected using an enzyme-linked immunosorbent assay (ELISA) (BDNF Emax ImmunoAssay system Kit, Promega Inc., Madison, WI, USA). Synapsin I, phosphosynapsin I, CREB, and phospho-CREB proteins were determined by western blot as previously described (Gómez-Pinilla et al., 2001a), quantified by densitometric scanning of the film under linear exposure conditions, and normalized for actin levels. Membranes were incubated with: anti-synapsin I (1:2000; Santa Cruz Biotechnology Inc., Santa Cruz, CA, USA), antiphospho-synapsin I (1:2000; Santa Cruz Biotechnology), antiCREB (1:1000; New England Biolabs Inc., Beverly, MA, USA), anti-phospho-CREB (1:1000; New England Biolabs Inc.), antiactin (1:2000; Santa Cruz Biotechnology) followed by an IgG horseradish peroxidase conjugate. Immunocomplexes were visualized by chemiluminescence using the ECL kit (Amersham Pharmacia Biotech Inc., Piscataway, NJ, USA).

\section{Immunohistochemistry}

Brain tissue was sliced in the sagittal plane $(30 \mu \mathrm{m})$, collected free floating in phosphate-buffered saline (PBS) and processed for BDNF and synapsin I immunohistochemistry as previously described (Gómez-Pinilla et al., 2001b). A 1:1000 dilution was used for the rabbit polyclonal anti-BDNF antisera (Chemicon International Inc., Temecula, CA, USA) and goat polyclonal anti-synapsin I (Santa Cruz Biotechnology).

\section{Cognitive performance}

The effect of 1 and 2 months of diet on cognitive function was assessed using the water maze in a separate cohort of rats $(n=16)$. In order to have experimentally homogeneous groups, we performed a water maze test before starting the diet period. According to these results, animals with comparable performance were distributed equally in both LFCC and HFS groups. The swimming pool $(130 \mathrm{~cm}$ diameter, $50 \mathrm{~cm}$ height $)$, with the escape platform (12 cm diameter) placed $1 \mathrm{~cm}$ beneath the water 
surface and $32 \mathrm{~cm}$ from the wall of the pool, was divided into four quadrants, i.e. platform (P), platform left (L), platform right $(\mathrm{R})$ and opposite $(\mathrm{O})$. The water $\left(24^{\circ} \mathrm{C}\right)$ was made opaque with white non-toxic biodegradable dye to prevent the rats from seeing the platform. The rats were trained on the water maze with 10 consecutive trials per day for 3 days. The animals were placed in the tank facing the wall at one of the equally spaced start locations that were randomly changed every trial. The spatial cues for reference around the pool were maintained constant throughout the experiment. Each trial lasted until the rat had found the platform or for a maximum of $2 \mathrm{~min}$. If the rat failed to find a platform, it was placed gently on the platform. At the end of each trial, the animals were allowed to rest on the platform for $1 \mathrm{~min}$. Time to locate the platform was recorded and an average latency was calculated from the values of 10 trials at each day. To assess spatial memory retention, spatial probe tests were performed 3 days after the last day of behavioral test by removing the platform from the pool. The rats were allowed to swim for $1 \mathrm{~min}$ in the pool without the escape platform, and the percentage of swim distance in each quadrant was calculated against the total distance.

\section{Statistical analyses}

GAPDH and actin were employed as internal standards for real-time RT-PCR and for western blot respectively, as their expressions were not altered by the diet. For quantification of TaqMan RT-PCR results, fluorescent signal intensities were plotted against the number of PCR cycles on a semilogarithmic scale (ABI sequence detector software version 1.6.3; PE Biosystem). Taqman EZ RT-PCR values for GAPDH were subtracted from BDNF, synapsin I, CREB, or GAP-43 values. The resulting corrected values were used to make comparisons across the different experimental groups. The mean values for the mRNA or protein levels were computed for the control (LFCC) and experimental (HFS) rats for each age group. Student's $t$-test (two tails, unpaired) was used for two-group comparisons. Linear regression analysis was performed on the individual samples to evaluate association between variables. An analysis of variance (ANOVA) with repeated measures was conducted for analyzing data from the water maze tests. The results were expressed as mean percent of control values for graphic clarity and represent the mean \pm S.E.M. of five to nine independent
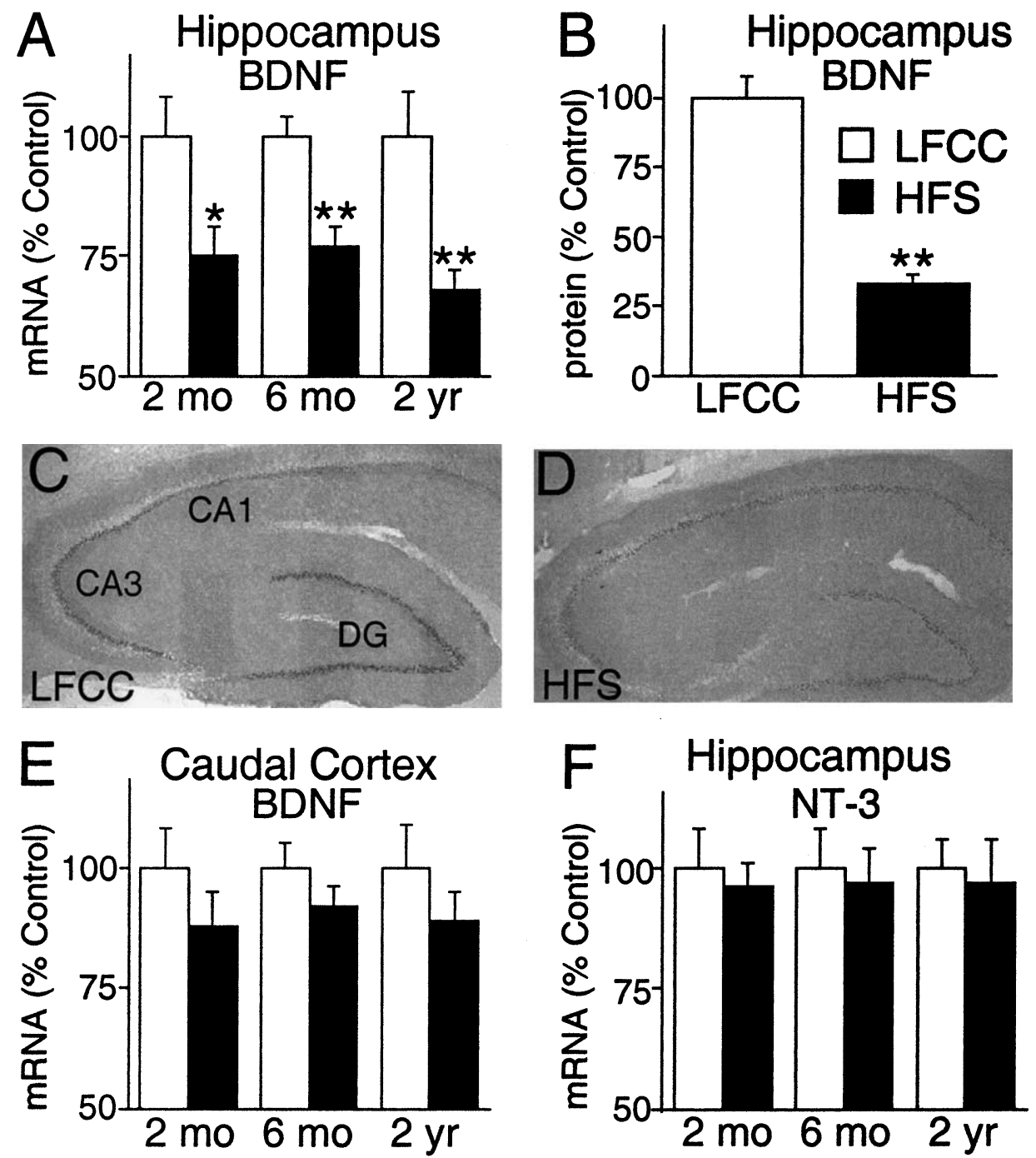

Fig. 1. Effects of HFS diet on BDNF mRNA and protein after different diet periods: 2 months $(2 \mathrm{mo}, n=10) ; 6$ months (6mo, $n=18) ; 2$ years $(2 \mathrm{yr}, n=12)$. (A) Hippocampal BDNF mRNA decreased in rodents maintained for 2 months $(75 \%)$, 6 months $(77 \%)$, and 2 years $(68 \%)$ on a HFS diet. (B) Reduction in BDNF (33\%) measured by ELISA, and (D) phenotypically evaluated by immunohistochemistry in sagittal sections of hippocampal tissue after 6 months of diet. (E) No changes in BDNF mRNA were observed in cerebral cortex, and $(F)$ no changes in NT-3 mRNA were observed in hippocampus. All HFS values are relative to LFCC diet. Each value represents the mean \pm S.E.M. $(* P<0.05$ and $* * P<0.01)$. DG, dentate gyrus. 
Hippocampus - Synapsin I

A

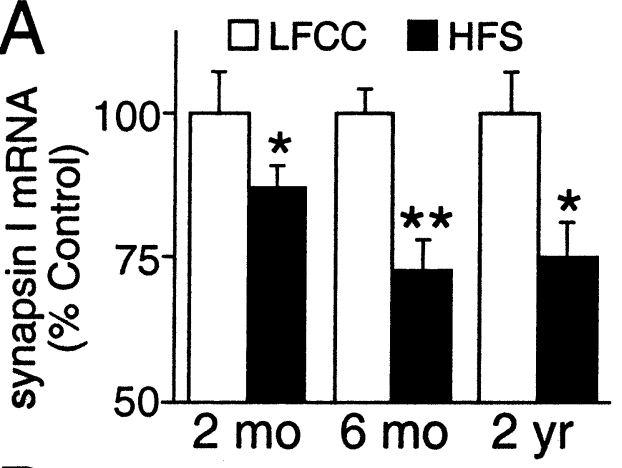

B

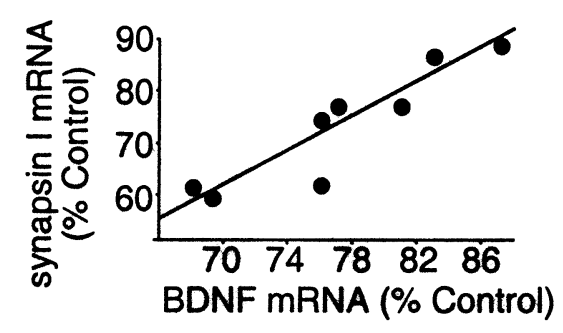

Hippocampus - Synapsin I

C

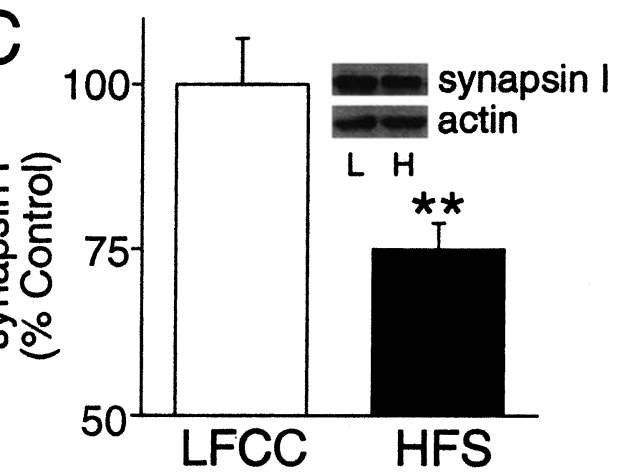

D

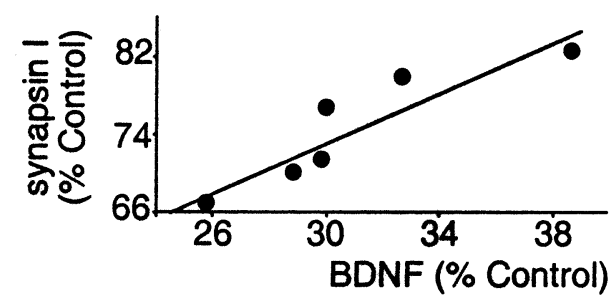

Cerebral Cortex - Synapsin I
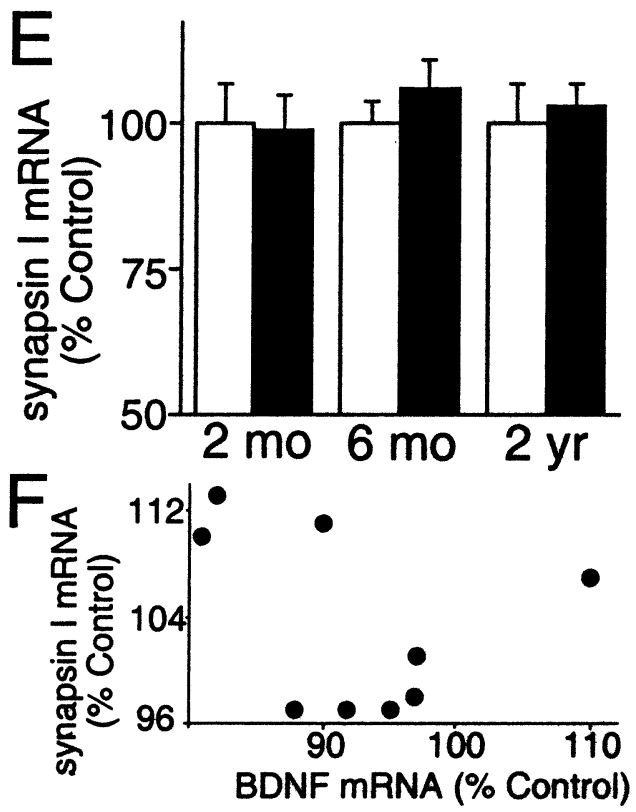

Hippocampus - P-synapsin I

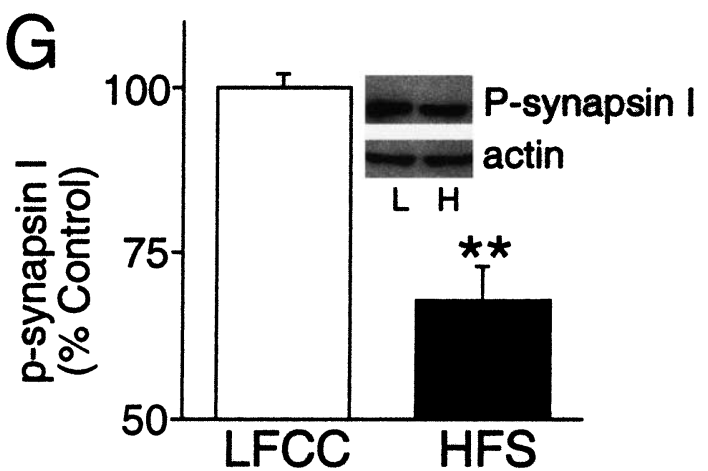

$\mathrm{H}$

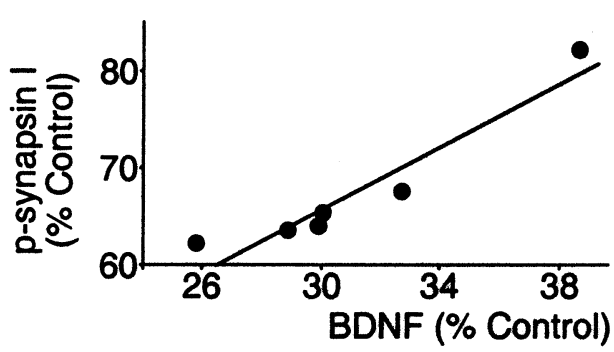

Hippocampus - Synapsin I
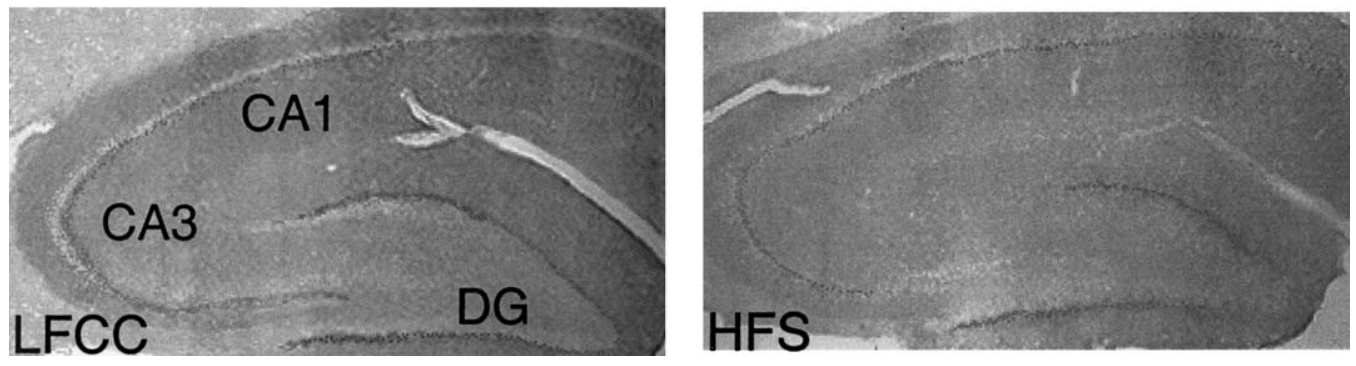

Fig. 2. 
determinations and were considered significant when $P$ values were $<0.05$

\section{RESULTS}

\section{$B D N F$ mRNA and protein}

Levels of BDNF mRNA in the hippocampus of rodents fed a HFS diet were reduced compared to rodents fed a LFCC diet, between 2 and 24 months. The lowest BDNF mRNA values were achieved after 2 years (Fig. 1A). Decreases in BDNF mRNA in the HFS group were accompanied by a dramatic reduction in BDNF protein assessed after 6 months on the diet (Fig. 1B). Decreases in BDNF protein affected select hippocampal subfields, as histological analysis showed a qualitative reduction in BDNF immunostaining in CA3 and dentate gyrus (Fig. 1D). There were no changes in BDNF mRNA related to diet in the cerebral cortex (Fig. 1E). We assessed NT-3 in hippocampal tissue to evaluate effects of diet on other members of the neurotrophin family. NT-3 mRNA levels were unchanged in HFS rats at all time points examined (Fig. 1F).

\section{Synapsin I $m R N A$ and protein}

Hippocampal levels of synapsin I mRNA were lower in rats fed the HFS diet compared to rats fed the LFCC diet at all time points examined (Fig. 2A). Western blot analysis performed at 6 months showed a significant reduction in total synapsin I (Fig. 2C) and phospho-synapsin I (Fig. 2G) in the hippocampus of rats fed HFS. Moreover, the decreases in BDNF were positively correlated with the decreases in synapsin $\mathrm{I}(r=0.91, P<0.01$; Fig. 2D) or phospho-synapsin I $(r=0.95, P<0.01$; Fig. 2H). In addition, the reductions in mRNA for BDNF and synapsin I were highly correlated at all time points examined $\left(r_{2 \mathrm{mo}}=0.96, P<0.01 ; r_{6 \mathrm{mo}}=0.92\right.$, $P<0.01 ; r_{2 \mathrm{yr}}=0.96, P<0.01$; graph shown in Fig. $2 \mathrm{~B}$ for 6 months). BDNF (Fig. 1C) and synapsin I (Fig. 2I) immunopositive neuronal elements were observed in the CA3 subregion and dentate granule layer of the hippocampal formation. These regions showed a qualitative reduction in BDNF and synapsin I staining intensity in rats fed the HFS diet. Decreases in synapsin I mRNA appeared specific to the hippocampus as no alterations related to the HFS diet were observed in the cerebral cortex (Fig. 2E), and there was no significant correlation between synapsin I mRNA and BDNF mRNA $\left(r_{2 \mathrm{mo}}=0.27, P=0.25 ; r_{6 \mathrm{mo}}=0.32, P=0.40 ; r_{2 \mathrm{yr}}=0.24\right.$,
$P=0.35$; shown for 6 months in Fig. $2 F$ ) at any time point examined.

\section{GAP-43 $m R N A$}

Levels of GAP-43 mRNA were significantly reduced in the hippocampus after 2 and 6 months of HFS diet (Fig. 3A) and correlated with levels of BDNF mRNA $\left(r_{2 \mathrm{mo}}=0.82, \quad P<0.01 ; \quad r_{6 \mathrm{mo}}=0.96, \quad P<0.01 ; \quad\right.$ graph shown for 6 months in Fig. 3B). Reductions in GAP43 mRNA were also correlated with the reduction in synapsin I mRNA $\left(r_{2 \mathrm{mo}}=0.87, P<0.01 ; r_{6 \mathrm{mo}}=0.98\right.$, $P<0.01$ ) (Fig. 3C). No changes in GAP-43 expression were detected in the cerebral cortex at any time point examined (Fig. 3D). There was no significant correlation between levels of GAP-43 and BDNF mRNAs $\left(r_{2 \mathrm{mo}}=0.29, P=0.35 ; r_{6 \mathrm{mo}}=0.30, P=0.68 ; r_{2 \mathrm{yr}}=0.22\right.$, $P=0.53$; graph shown for 6 months in Fig. 3E), or GAP-43 and synapsin I mRNAs $\left(r_{2 \mathrm{mo}}=0.13, P=0.69\right.$; $r_{6 \mathrm{mo}}=0.32 ; \quad r_{2 \mathrm{yr}}=0.50, \quad P=0.13 ;$ graph shown for 6 months in Fig. 3F) in the cerebral cortex.

\section{CREB $\mathrm{MRNA}$ and protein}

CREB mRNA levels were reduced in the hippocampus (Fig. 4A) but not in the cerebral cortex (Fig. 4E) of rats fed the HFS diet for 6 months or 2 years. Western blot showed lower levels of phospho-CREB (Fig. 4C) and total CREB (Fig. 4G) in the HFS group following 6 months of diet compared to the LFCC group. CREB values (phosphorylated, $r=0.88, P<0.01$; Fig. $4 \mathrm{D}$; total, $r=0.98, P<0.01$; Fig. $4 \mathrm{H}$ ) were positively correlated with BDNF values. Levels of BDNF mRNA and CREB mRNA were correlated at 6 months and 2 years of diet in the hippocampus $\left(r_{6 \mathrm{mo}}=0.91, P<0.01\right.$; $r_{2 \mathrm{yr}}=0.82, P<0.01$; graph shown for 6 months in Fig. 4B) but not in the cerebral cortex $\left(r_{6 \mathrm{mo}}=0.44\right.$, $P=0.23 ; r_{2 \mathrm{yr}}=0.37, P=0.27$; graph shown for 6 months in Fig. 4F).

\section{Spatial learning in rats fed HFS diet}

Rats maintained for 1 or 2 months on the HFS diet required more time than $\mathrm{LFCC}$ rats to find the platform (Fig. 5A). After 1 month of diet, the mean escape latency for the HFS group was significantly longer than for the LFCC rats $(P<0.05$; Fig. 5A). After 2 months of diet, the mean escape latency for the HFS group was longer than the LFCC rats for all 3 days of testing $(P<0.05$; Fig. 5A). These results were significantly correlated with the reduced hippocampal BDNF levels (Fig. 6E, F). The

Fig. 2. Effects of HFS diet on synapsin I mRNA and protein. (A) Decreases in hippocampal synapsin I mRNA after 2 months $(2 \mathrm{mo}, 87 \%), 6$ months $(6 \mathrm{mo}, 73 \%)$, and 2 years $(2 \mathrm{yr}, 75 \%)$ of HFS diet. (B) A positive correlation was found between decreases in BDNF and synapsin I mRNAs (shown for 6 months, $r=0.92, P<0.01$ ). (C) Reduction of hippocampal synapsin I (75\%), and $(\mathrm{G})$ phospho $(\mathrm{P})$-synapsin I $(68 \%)$ were positively correlated with BDNF levels (D, H; shown for 6 months; synapsin I, $r=0.91, P<0.01$; phospho-synapsin I, $r=0.95, P<0.01)$. In the cerebral cortex, synapsin I mRNA was unchanged (E), and was not correlated (F) with BDNF mRNA. (I) Typical synapsin I immunostaining in sagittal sections of hippocampus is shown for LFCC and HFS animals after 6 months on diet. Each value represents the mean \pm S.E.M. $\left({ }^{*} P<0.05\right.$ and $\left.{ }^{* *} P<0.01\right)$. DG, dentate gyrus. 


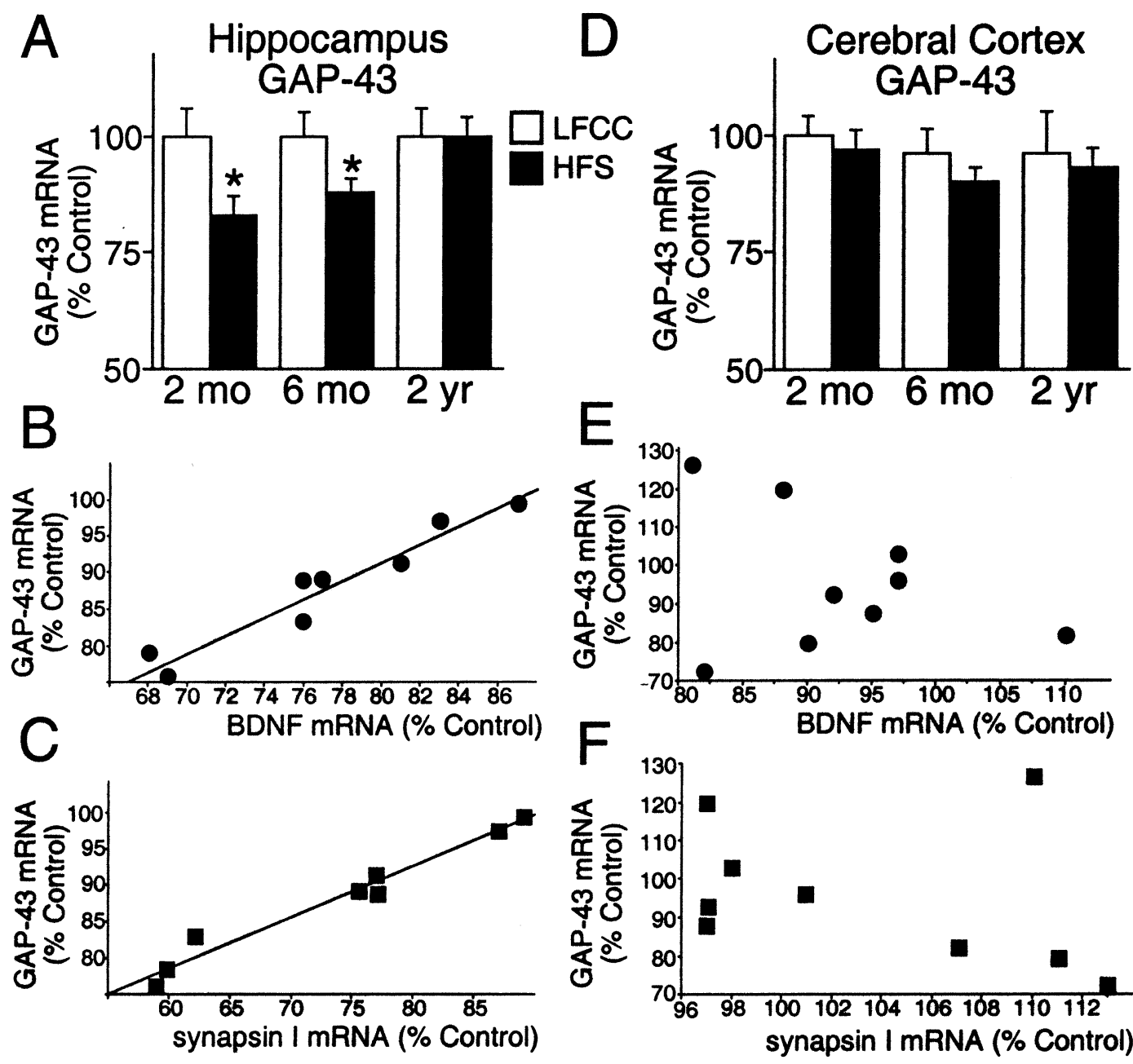

Fig. 3. Effects of HFS diet on GAP-43 expression. (A) Decreases in hippocampal GAP-43 mRNA after 2 months (2mo, $83 \%)$ and 6 months $(6 \mathrm{mo}, 88 \%)$ of HFS diet. A high, positive correlation was found between (B) decreases in GAP-43 and BDNF mRNAs, and (C) decreases in GAP-43 and synapsin I mRNAs (shown for 6 months, left; $r_{\text {BDNF }}=0.96, P<0.01$; $r_{\text {synapsin }}=0.98, P<0.01$ ). (D) GAP-43 mRNA was unchanged in cerebral cortex and there was no correlation between GAP43 and BDNF (E), or GAP-43 and synapsin I (F) mRNAs. Each value represents the mean \pm S.E.M. $\left({ }^{*} P<0.05\right)$. $2 \mathrm{yr}, 2$ years.

escape latency in the HFS group at the beginning of the second testing period (month 2 ) tended to be higher than at the end of the first testing period (month 1), relative to the LFCC group. After removal of the escape platform by the end of the second testing period, rats fed the HFS diet swam randomly across the four quadrants, as no significant difference was found in the swimming distances among the four quadrants (Fig. 5C, right), and we found a high correlation between these results and the BDNF levels (Fig. 6G, H).

\section{Spatial learning in rats fed regular diet (LFCC)}

Escape latency scores for each rat tested in the water maze were compared with levels of BDNF mRNA and protein using linear regression analysis (Fig. 6). Results showed a positive correlation such that rats with longer escape latency had lower levels of BDNF mRNA and protein in the hippocampus (Fig. 6A, B). The platform was removed at the end of the second testing period to evaluate memory retention. LFCC animals swam pre- dominantly in the quadrant where the platform was located (platform quadrant, Fig. 5B, left) as shown by a significant longer distance swam in the platform quadrant relative to the other three quadrants $(45 \pm 1 \%$, Fig. 5C, left). These results were highly correlated with the levels of BDNF mRNA and protein (Fig. 6C, D)

\section{DISCUSSION}

The present study provides novel evidence on the effects of diet on neuronal plasticity and function via regulation of $\mathrm{BDNF}$, in the absence of other risk factors associated to cardiovascular dysfunction. Spatial learning performance was associated with hippocampal levels of BDNF, such that animals with higher levels of BDNF performed better. Consuming a HFS diet decreased hippocampal BDNF mRNA and protein, and performance in the water maze. There were no alterations associated to the diet in NT-3, which is also expressed in hippo- 


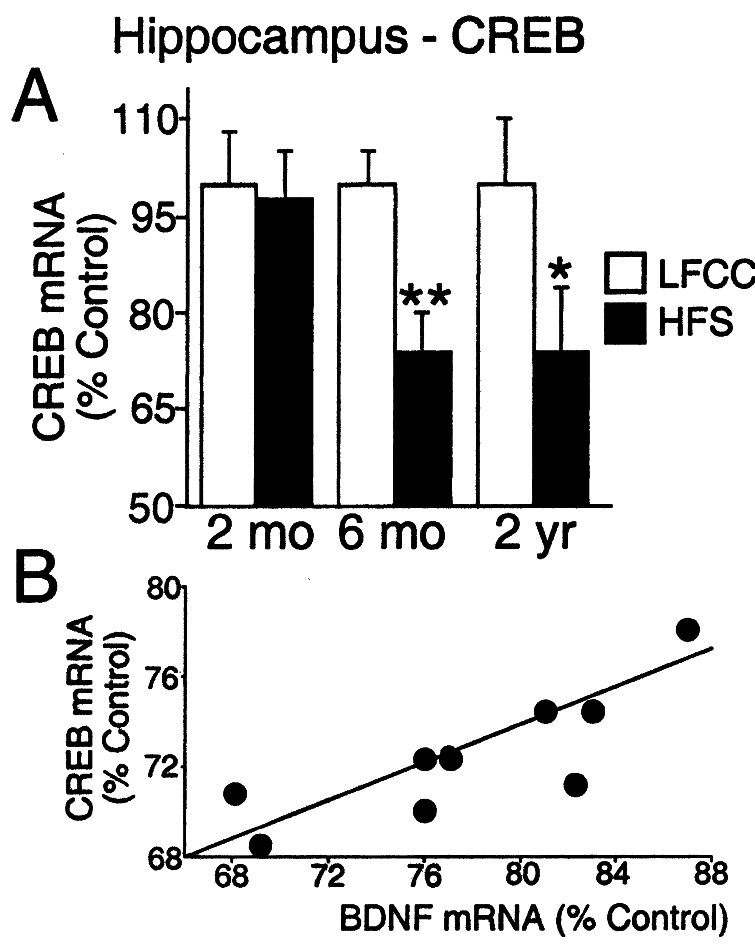

\section{Cerebral Cortex - CREB}
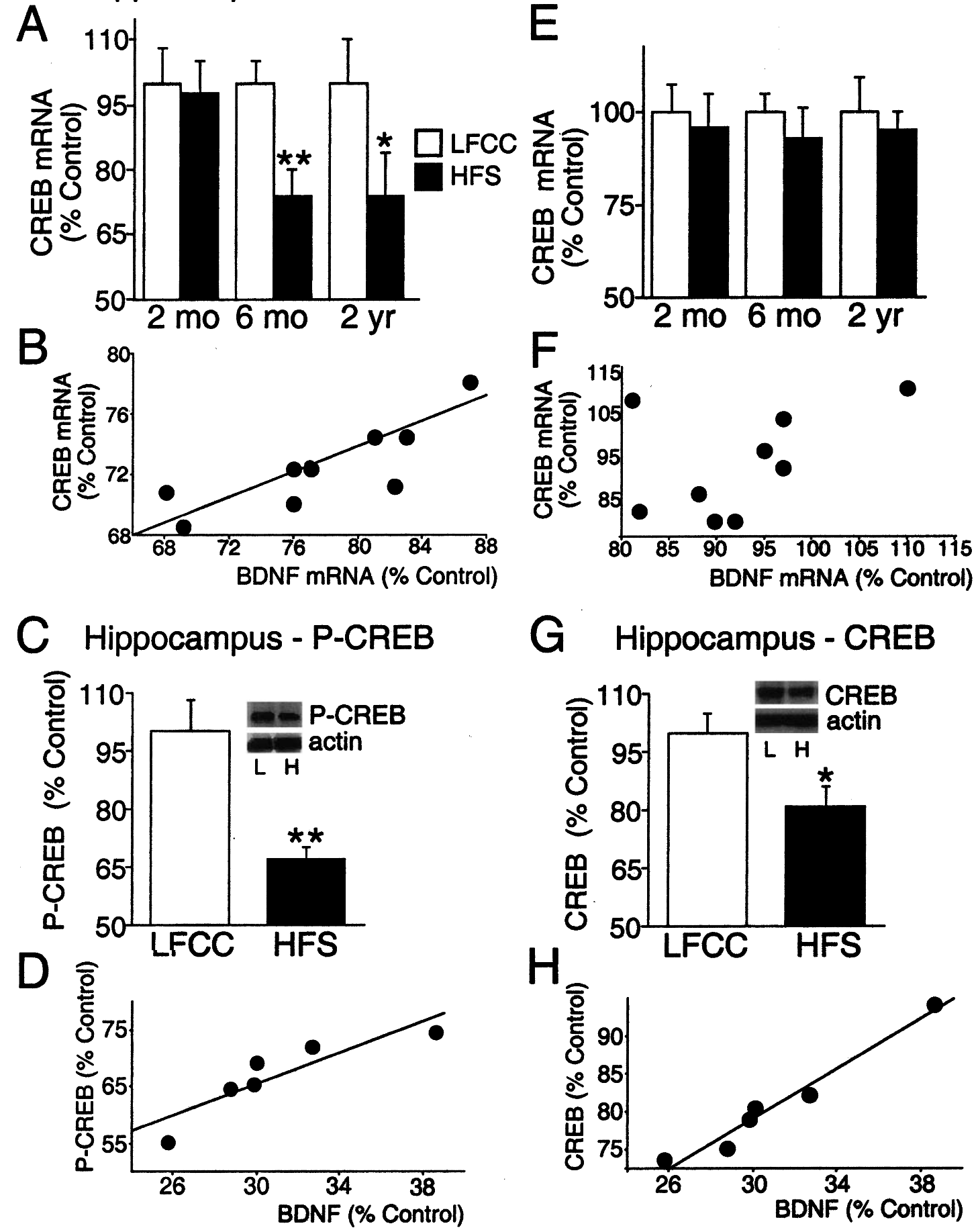

G Hippocampus - CREB

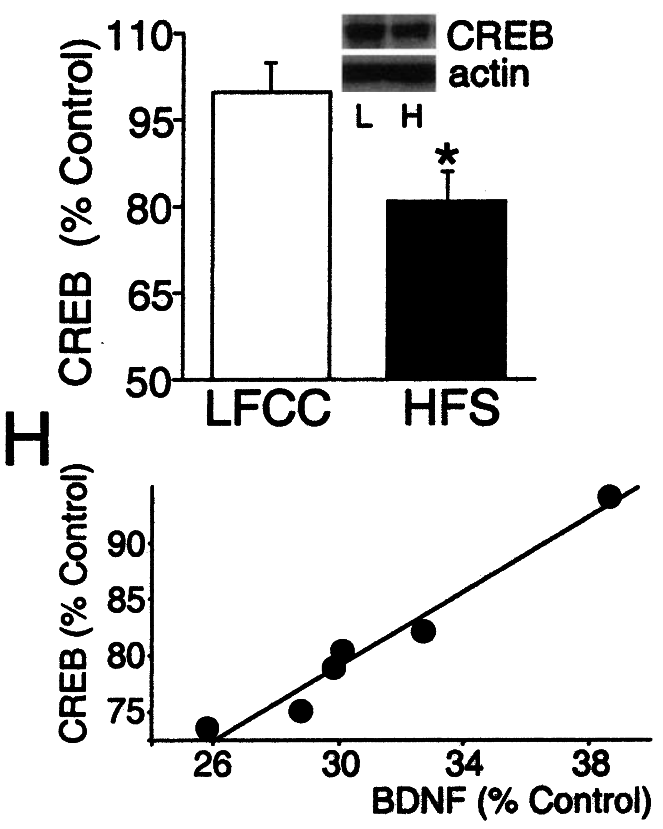

Fig. 4. Effects of HFS diet on CREB expression. (A) CREB mRNA was reduced in hippocampus after 6 months (6mo, $74 \%$ ) and 2 years $(2 \mathrm{yr}, 74 \%)$ of HFS diet, and (B) there was a positive correlation between CREB and BDNF mRNAs (shown for 6 months $r=0.91, P<0.01$ ). (E) In the cerebral cortex, no changes in CREB expression were detected and (F) there was no correlation between CREB and BDNF mRNAs. (C) Reduced hippocampal phospho (P)-CREB (67\%), and (G) CREB (81\%) were measured after 6 months of HFS diet. Each value represents the mean \pm S.E.M. $\left({ }^{*} P<0.05\right.$ and $\left.{ }^{* *} P<0.01\right)$. A high, positive correlation was found between (D) decreases in P-CREB and BDNF, and (H) decreases in CREB and BDNF.

campal neurons. Decreases in BDNF mRNA and protein were associated with reduction of molecules involved with synaptic function, neuronal growth, and cognitive function. Increasing evidence indicates that BDNF has the capacity to convert changes in electrical activity to long-lasting changes in synaptic strength and function (Poo, 2001; Schinder and Poo, 2000). Therefore, BDNF reduction resulting from the HFS diet may 

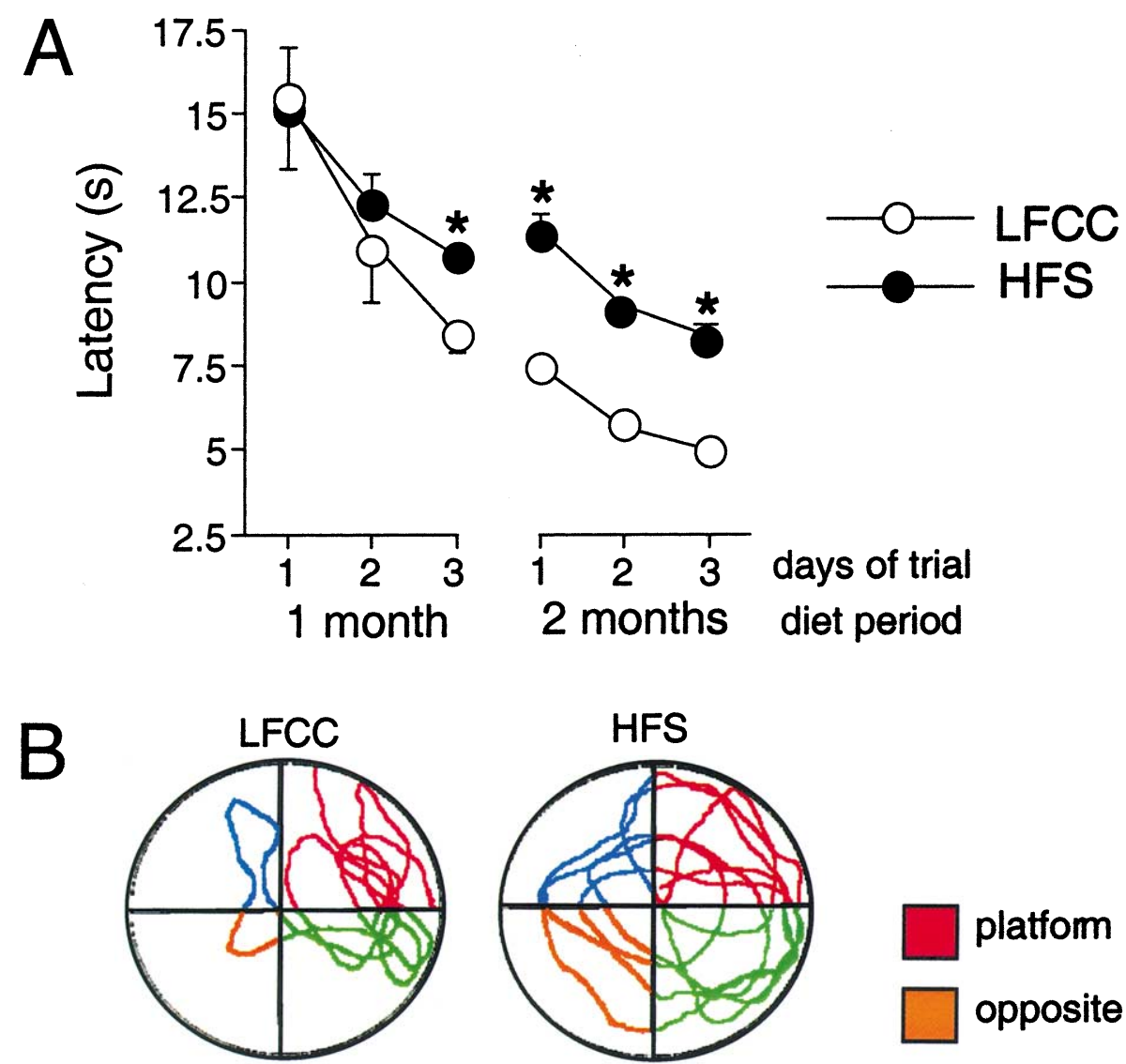

platform
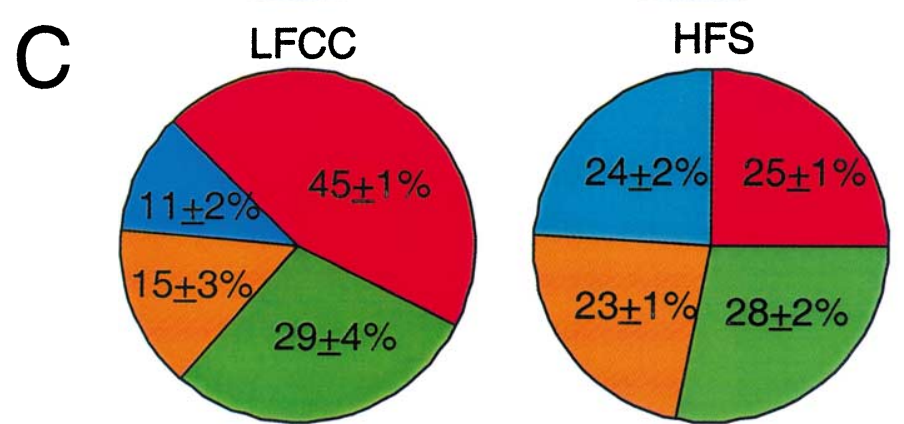

opposite

right

left

Fig. 5. Effects of HFS diet on spatial learning using the water maze. (A) The latency to find the platform was higher in the HFS rats. (B) Representative samples of trails traveled during the spatial probe test illustrating preference of rats fed the LFCC diet to swim in the platform quadrant (left) vs. random swimming of rats fed the HFS diet (right). (C) Distribution of the average percent of swimming distances for the four quadrants. Each section represents the mean \pm S.E.M. $\left({ }^{*} P<0.01\right.$ relative to LFCC controls).

lower the neurochemical substrate of the hippocampus required for optimal neuronal performance.

\section{A HFS diet reduces levels of BDNF in the hippocampus and learning performance}

We have previously shown that rats learning a spatial memory task have elevated expression of BDNF mRNA in the hippocampus (Kesslak et al., 1998). The present results indicate that small differences in hippocampal BDNF can be critical for spatial learning performance. Animals with higher hippocampal BDNF required less time to find the platform in the water maze, and showed a clear preference for the platform quadrant in the spa- tial probe test. Consuming the HFS diet reduced BDNF mRNA and protein at the earliest time point examined ( 2 months: mRNA, $-24 \%$; protein $-39 \%$ ) and resulted in further reduction with diet consumption (6 months: mRNA, $-26 \%$; protein, $-67 \%, 2$ years: mRNA, $-42 \%$ ). Reduced levels of BDNF were associated with deficiency in learning spatial information (Fig. 5E, F, G, $\mathrm{H})$ and in the capacity to retain this information. Spatial learning in the water maze relies primarily on hippocampal function (Korol et al., 1993), and spatial learning is impaired in rodents lacking BDNF gene (Linnarsson et al., 1997), infused with a BDNF blocking antibody $(\mathrm{Mu}$ et al., 1999), or with an antisense BDNF oligonucleotide (Mizuno et al., 2000). 
A

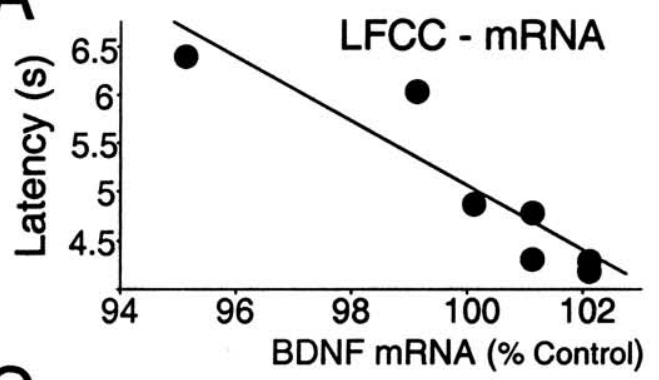

C
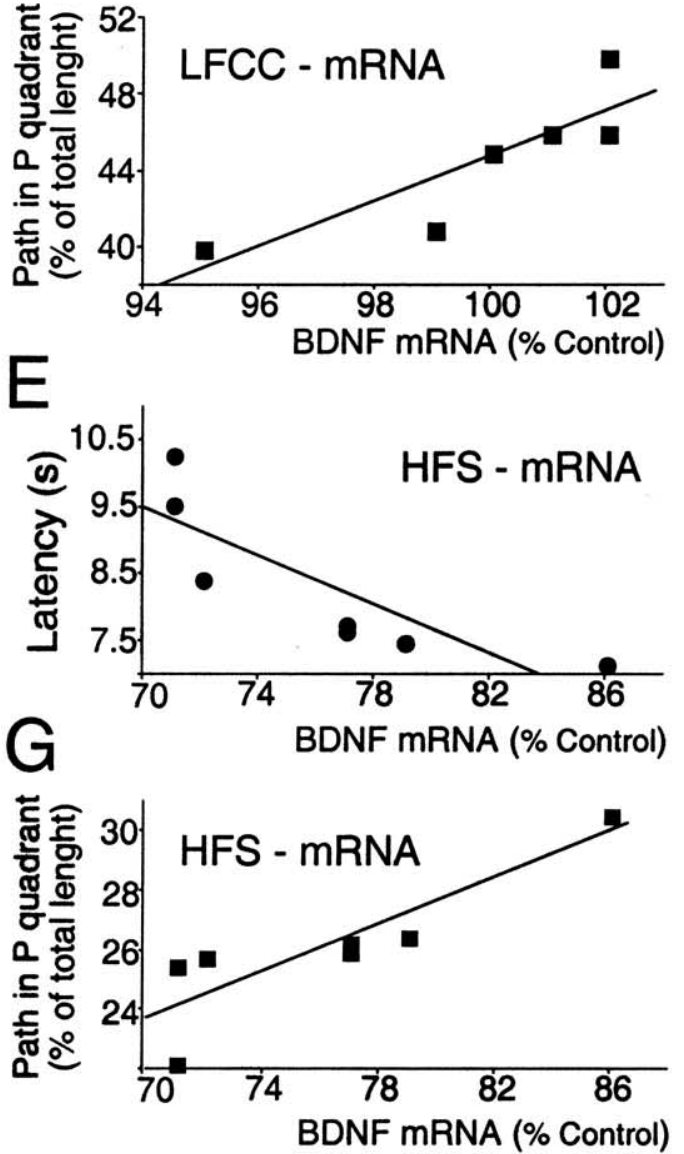

B

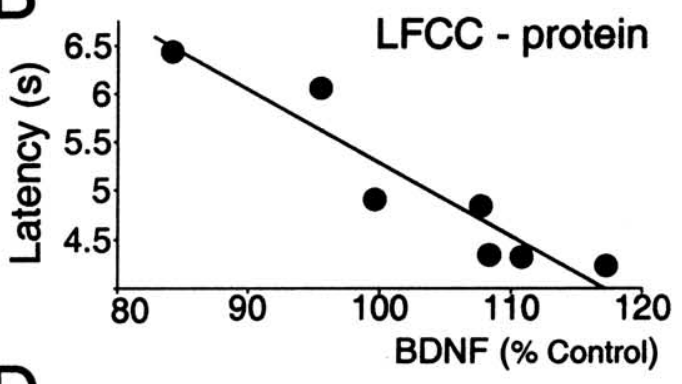

$\mathrm{D}$
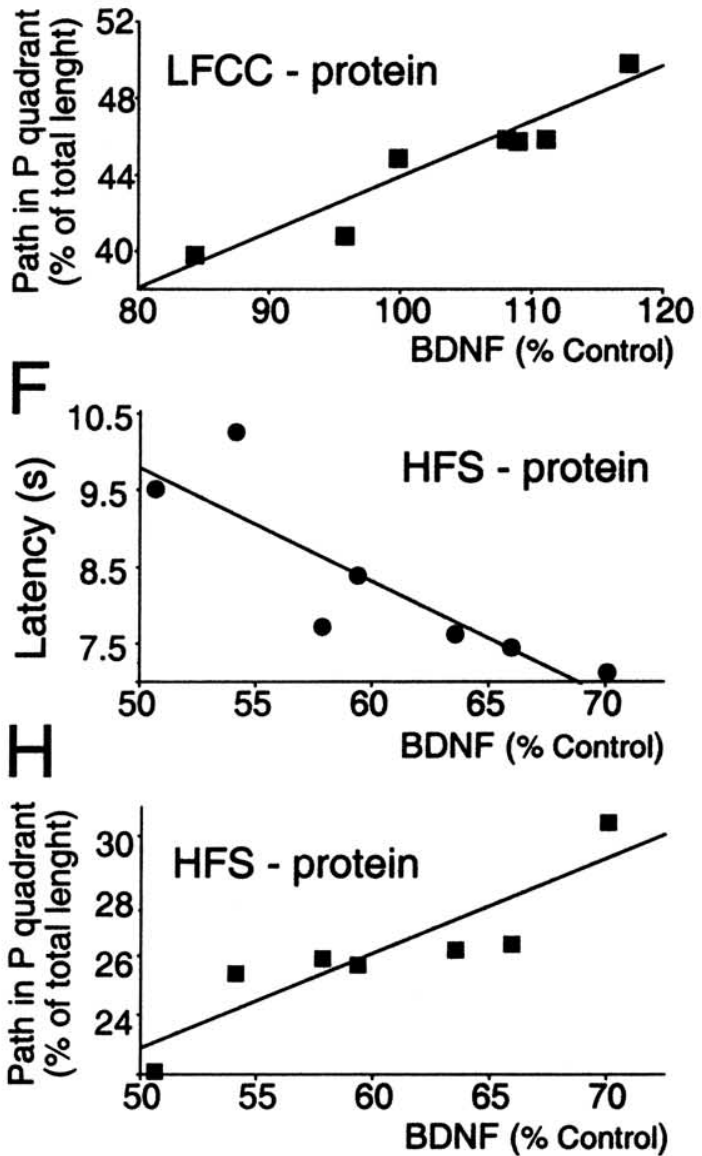

Fig. 6. Association between BDNF (mRNA and protein) and spatial learning. A significant negative correlation was found between hippocampal BDNF mRNA (A, $r=0.92, P<0.01)$, or protein $(\mathrm{B}, r=0.94, P<0.01)$, vs. the latency required to find the hidden platform in LFCC animals. The levels of BDNF were positively correlated with the distance swam in the platform (P) quadrant $(\mathrm{C}, r=0.86, P<0.05$; D $, r=0.95, P<0.01)$ after the platform was removed. In the HFS group, BDNF mRNA (E) and BDNF protein (F) levels were significantly negatively correlated with the latency (mRNA: $r=0.83, P<0.05$; protein: $r=0.86, P<0.05)$, and positively correlated with the swimming distance within the platform quadrant $(\mathrm{G}, \mathrm{H})$. Spatial learning was evaluated using the water maze.

\section{Diet and BDNF impact neuronal plasticity}

Memory formation involves short-term changes in electrical properties (Barnes, 1995; Ito, 1986), and long-term structural alterations of synapses (Burns and Augustine, 1995; Edwards, 1995). As discussed, cellular and molecular events involved with these processes are under the range of action of BDNF (Poo, 2001).

Levels of phosphorylated protein, total protein, and mRNA for synapsin I decreased in the hippocampus of
HFS rats. Levels of synapsin I mRNA decreased according to BDNF mRNA values detected using linear regression analysis. The same type of analysis showed that decreases in synapsin I protein (total and phosphorylated) were associated with comparable decreases in BDNF. It is likely that diet may elicit coordinated responses of the BDNF and synapsin I systems, and/or BDNF may affect synapsin I at the transcriptional and post-translational levels. In a separate set of experiments (S. Vaynman, Z. Ying and F. Gómez-Pinilla, unpublished 
observations) we have blocked BDNF action in the hippocampus using the tyrosine kinase receptor blocker $\mathrm{K} 252 \mathrm{a}$, resulting in decreases in synapsin I mRNA. These results suggest that a reduction in BDNF levels can affect synapsin I activity or function, as it is known that BDNF facilitates synaptic transmission by enhancing synapsin I phosphorylation (Greengard et al., 1993; Jovanovic et al., 2000).

Results also showed that GAP-43 expression was reduced in the hippocampus of animals fed HFS diet for 2 and 6 months, and this was correlated with BDNF and synapsin I levels. GAP-43 has been implicated in input-dependent alterations of synaptic morphology (Benowitz and Routtenberg, 1997) that may be associated with learning and memory (Routtenberg et al., 2000). GAP-43 was not reduced after 2 years of HFS diet which may be related to a compensatory mechanism, since other molecules can regulate GAP-43 (Benowitz and Routtenberg, 1997). Results suggest that the HFS diet can affect growth and function of axonal terminals required for maintenance of neural circuits.

The HFS diet also reduced levels of CREB mRNA and CREB protein (phosphorylated and total) and these reductions were positively correlated with BDNF levels. CREB can regulate BDNF gene transcription in a calcium-dependent mechanism (Finkbeiner, 2000). In turn, BDNF causes the phosphorylation of CREB at the transcriptional regulatory site Ser-133, resulting in CREB activation and gene transcription (Finkbeiner et al., 1997; McAllister et al., 1999). Reduced levels of CREB in hippocampal slices have been shown to impair maintenance of long-term potentiation (Bourtchuladze et al., 1994), a postulated mechanism for certain forms of learning. CREB-mediated transcription is important for learning and memory in various species (Silva et al., 1998). It is intriguing that deficits in spatial learning by 2 months of a HFS diet appeared to have occurred in the absence of changes in CREB mRNA. These results seem to point to a progressive deterioration in response to the HFS diet as additional molecular systems such as CREB become involved with time.

\section{How diet may impact neuronal plasticity}

Although other physiological parameters may contribute to the effects of a HFS diet on neuroplasticity, we can exclude hypertension and atherosclerosis as primary causes, at least during the first year. Female rats, like the ones used in the present study, do not develop hypertension until after 12 months on a HFS diet (Roberts et al., 2000), and do not show atherosclerosis as they have low cholesterol levels (Barnard et al., 1993). Therefore, hypertension and atherosclerosis cannot account for decreases in BDNF, synapsin I, and GAP-43, which started as early as 2 months on the HFS diet. We can also exclude obesity as a factor for decreased activity resulting in lowered levels of BDNF during the first
6 months. HFS animals did not become heavier until by week 25 on the diet (LFCC vs. HFS: $188 \pm 1.4 \mathrm{~g}$ vs. $214 \pm 3.4 \mathrm{~g}, P<0.01$ ), and this difference remained significant throughout the remainder of the study. Moreover, the HFS and LFCC groups had similar energy consumption (Roberts et al., 2000) and there were no significant differences in daily cage activity between HFS $\left(220 \pm 5 \times 10^{2}\right.$ counts $)$ and LFCC animals $\left(188 \pm 15 \times 10^{2}\right.$ counts $)$ that could explain a decrease in BDNF with the HFS diet.

The fact that the HFS diet causes insulin resistance (Barnard et al., 1998) resulting in high blood levels of insulin suggests that hyperinsulinemia may be a factor in our experimental design. A putative action of insulin, however, would be compensatory or neuroprotective as insulin may facilitate learning and memory (Wickelgren, 1998; Zhao et al., 1999). The production of free radicals such as superoxide may be a variable for the effects of diet on the brain. Although there is no evidence in the brain, it is known that a high-sugar or high-fat diet can increase free radical production in other organs such as the liver (Faure et al., 1997; Slim et al., 1996), and that antioxidant therapy can reduce free radical formation (Joseph et al., 1999). Neurotrophic factors such as BDNF protect neurons against oxidative stress (Cheng and Mattson, 1994) and stabilize cellular calcium homeostasis (Mattson et al., 1995). Further studies are required to clarify the interaction between dietary factors, oxidative stress, and BDNF. Nevertheless, our data seem to indicate that a decrease in BDNF is a critical variable involved with the decrease in neuroplasticity and cognitive function associated with consumption of the HFS diet.

BDNF has a critical role in synaptic function, neuronal growth, and behavior, and our results show that several of these functions can be compromised following consumption of a HFS diet. For example, HFS diet can attenuate neurotransmitter release that is generally modulated by BDNF and synapsin I. Changes in BDNF, synapsin I, GAP-43, and CREB in response to the HFS diet appeared unique to the hippocampus since no alterations were observed in the occipital cortex, although the later region is highly susceptible to environmental challenges (Klintsova and Greenough, 1999). The hippocampus is involved with associative learning, and is the primary target of neurodegenerative diseases resulting in memory impairment. It is well documented that BDNF can protect neurons from insult or disease (McAllister et al., 1999; Thoenen, 1995). Therefore, the reductions of BDNF resulting from a HFS diet may deprive neurons of their natural protection to aging, insults, or disease.

Acknowledgements - We thank V.R. Edgerton and J. Twiss for critical comments on the manuscript, and S. Vaynman for assistance with the Morris water maze testing. This study was supported by NIH awards NS 38978 and NS 39522. 


\section{REFERENCES}

Baekelandt, V., Arckens, L., Annaert, W., Eysel, U.T., Orban, G.A., Vandesande, F., 1994. Alterations in GAP-43 and synapsin immunoreactivity provide evidence for synaptic reorganization in adult cat dorsal lateral geniculate nucleus following retinal lesions. Eur. J. Neurosci. 6, $754-765$.

Barnard, R.J., Faria, D.J., Menges, J.E., Martin, D.A., 1993. Effects of a high-fat, sucrose diet on serum insulin and related atherosclerotic risk factors in rats. Atherosclerosis 100, 229-236.

Barnard, R.J., Roberts, C.K., Varon, S.M., Berger, J.J., 1998. Diet-induced insulin resistance precedes other aspects of the metabolic syndrome. J. Appl. Physiol. 84, 1311-1315.

Barnes, C.A., 1995. Involvement of LTP in memory: are we 'searching under the street light'? Neuron 15, 751-754.

Benowitz, L.I., Routtenberg, A., 1997. GAP-43: an intrinsic determinant of neuronal development and plasticity. Trends Neurosci. 20 , 84-91.

Block, G., Roserberger, W.F., Paterson, B.H., 1988. Calories, fat and cholesterol: intake patterns in the U.S. population by race, sex and age. Am. J. Public Health 78, 1150-1155.

Bourtchuladze, R., Frenguelli, B., Blendy, J., Cioffi, D., Schutz, G., Silva, A.J., 1994. Deficient long-term memory in mice with a targeted mutation of the cAMP-responsive element-binding protein. Cell 79, 59-68.

Brock, T.O., O'Callaghan, J.P., 1987. Quantitative changes in the synaptic vesicle proteins synapsin I and p38 and the astrocyte-specific protein glial fibrillary acidic protein are associated with chemical-induced injury to the rat central nervous system. J. Neurosci. 7, 931-942.

Burns, M.E., Augustine, G.J., 1995. Synaptic structure and function: dynamic organization yields architectural precision. Cell 83, 187-194.

Castrén, E., Berninger, B., Leingärtner, A., Lindholm, D., 1998. Regulation of brain-derived neurotrophic factor mRNA levels in hippocampus by neuronal activity. Progr. Brain Res. 117, 57-64.

Cheng, B., Mattson, M.P., 1994. NT-3 and BDNF protect CNS neurons against metabolic/excitotoxic insults. Brain Res. 640 , 56-67.

Edwards, F.A., 1995. Anatomy and electrophysiology of fast central synapses leads to a structural model for long-term potentiation. Physiol. Rev. 75, 759-787

Faure, P., Rossini, E., Lafond, J.L., Richard, M.J., Favier, A., Halimi, S., 1997. Vitamin E improves the free radicals defence system potential and insuline sensitivity of rats fed high fructose diet. J. Nutr. 127, 103-107.

Finkbeiner, S., 2000. Calcium regulation of the brain-derived neurotrophic factor gene. Cell. Mol. Life Sci. 57, 394 401.

Finkbeiner, S., Tavazoie, S.F., Maloratsky, A., Jacobs, K.M., Harris, K.M., Greenberg, M.E., 1997. CREB: a major mediator of neuronal neurotrophin responses. Neuron 19, 1031-1047.

Gómez-Pinilla, F., So, V., Kesslak, J.P., 2001a. Spatial learning induces neurotrophin receptor and synapsin I in the hippocampus. Brain Res. 904, 13-19.

Gómez-Pinilla, F., Ying, Z., Opazo, P., Roy, R.R., Edgerton, V.R., 2001b. Differential regulation by exercise of BDNF and NT-3 in rat spinal cord and skeletal muscle. Eur. J. Neurosci. 13, 1078-1084.

Greengard, P., Valtorta, F., Czernik, A.J., Benfenati, F., 1993. Synaptic vesicle phosphoproteins and regulation of synaptic function. Science 259, $780-785$.

Ito, M., 1986. Long-term depression as a memory process in the cerebellum. Neurosci. Res. 3, 531-539.

Joseph, J.A., Shukitt-Hale, B., Denisova, N.A., Bielinski, D., Martin, A., McEwen, J.J., Bickford, P.C., 1999. Reversals of age-related declines in neuronal signal transduction, cognitive, and motor behavioral deficits with blueberry, spinach, or strawberry dietary supplementation. J. Neurosci. 19, 8114-8121.

Jovanovic, J.N., Benfenati, F., Stow, Y.L., Sihra, S., Sanghera, J.S., Pelecch, S.L., Greengard, P., Czernik, A.J., 1996. Neurotrophins stimulate phosphorylation of synapsin I by MAP kinase and regulate synapsin I-actin interactions. Proc. Natl. Acad. Sci. USA 93, 3679-3683.

Jovanovic, J.N., Czernik, A.J., Fienberg, A.A., Greengard, P., Sihra, T.S., 2000. Synapsins as mediators of BDNF-enhanced neurotransmitter release. Nat. Neurosci. 3, 323-329.

Kalmijn, S., Foley, D., White, L., Burchfiel, C.M., Curb, J.D., Petrovitch, H., Ross, G.W., Havlik, R.J., Launer, L.J., 2000. Metabolic cardiovascular syndrome and risk of dementia in japanese-american elderly men: the honolulu-asia aging study. Arterioscler. Thromb. Vasc. Biol. 20, 2255-2260.

Kalmijn, S., Launer, L.J., Ott, A., Witteman, J.C., Hofman, A., Breteler, M.M., 1997. Dietary fat intake and the risk of incident dementia in the Rotterdam Study. Ann. Neurol. 42, 776-782.

Kesslak, J.P., So, V., Choi, J., Cotman, C.W., Gomez-Pinilla, F., 1998. Learning upregulates brain-derived neurotrophic factor messenger ribonucleic acid: a mechanism to facilitate encoding and circuit maintenance? Behav. Neurosci. 112, 1012-1019.

Klintsova, A.Y., Greenough, W.T., 1999. Synaptic plasticity in cortical systems. Curr. Opin. Neurobiol. 9, 203-208.

Knopman, D., Boland, L.L., Mosley, T., Howard, G., Liao, D., Szklo, M., McGovern, P., Folsom, A.R., 2001. Cardiovascular risk factors and cognitive decline in middle-aged adults. Neurology $56,42-48$.

Korol, D.L., Abel, T.W., Curch, L.T., Barnes, C.A., McNaughton, B.L., 1993. Hippocampal synaptic enhancement and spatial learning in the Morris swim task. Hippocampus 3, 127-132.

Linnarsson, S., Bjorklund, A., Ernfors, P., 1997. Learning deficit in BDNF mutant mice. Eur. J. Neurosci. 9, $2581-2587$.

Mattson, M.P., Lovell, M.A., Furukawa, K., Markesbery, W.R., 1995. Neurotrophic factors attenuate glutamate-induced accumulation of peroxides, elevation of intracellular $\mathrm{Ca} 2+$ concentration, and neurotoxicity and increase antioxidant enzyme activities in hippocampal neurons. J. Neurochem. 65, 1740-1751

McAllister, A.K., Katz, L.C., Lo, D.C., 1999. Neurotrophins and synaptic plasticity. Annu. Rev. Neurosci. 22, $295-318$.

Melloni, H., Apostolides, P.J., Hamos, J.E., DeGennaro, L.J., 1994. Dynamics of synapsin I gene expression during the establishment and restoration of functional synapses in the rat hippocampus. Neuroscience 58, 683-703.

Mizuno, M., Yamada, K., Olariu, A., Nawa, H., Nabeshima, T., 2000. Involvement of brain-derived neurotrophic factors in spatial memory formation and maintenance in a radial arm maze test in rats. J. Neurosci. 20, 7116-7121.

Mu, J.S., Li, W.P., Yao, Z.B., Zhou, X.F., 1999. Deprivation of endogenous brain-derived neurotrophic factor results in impairment of spatial learning and memory in adult rats. Brain Res. 835, 259-265.

Oestreicher, A.B., De Graan, P.N., Gispen, W.H., Verhaagen, J., Schrama, L.H., 1997. B-50, the growth associated protein-43: modulation of cell morphology and communication in the nervous system. Prog. Neurobiol. 53, 627-686.

Poo, M.-m., 2001. Neurotrophins as a synaptic modulator. Nat. Rev. Neurosci. 2, 24-32.

Roberts, C.K., Vaziri, N.D., Wang, X.Q., Barnard, R.J., 2000. Enhanced NO inactivation and hypertension induced by a high-fat, refinedcarbohydrate diet. Hypertension 36, 423-429.

Routtenberg, A., Cantallops, I., Zaffuto, S., Serrano, P., Namgung, U., 2000. Enhanced learning after genetic overexpression of a brain growth protein. Proc. Natl. Acad. Sci. USA 97, 7657-7662.

Schinder, A.F., Poo, M.-m., 2000. The neurotrophin hypothesis for synaptic plasticity. Trends Neurosci. 23, 639-645. 
Shaywitz, A.J., Greenberg, M.E., 1999. CREB: a stimulus-induced transcription factor activated by a diverse array of extracellular signals. Annu. Rev. Biochem. 68, 821-861.

Silva, A.J., Kogan, J.H., Frankland, P.W., Kida, S., 1998. CREB and memory. Annu. Rev. Neurosci. 21, $127-148$.

Slim, R.M., Toborek, M., Watkins, B.A., Boissonneault, G.A., Hennig, B., 1996. Susceptibility to hepatic oxidative stress in rabbits fed different animal and plant fats. J. Am. Coll. Nutr. 15, 289-294.

Taubes, G., 2001. The soft science of dietary fat. Science 291, 2536-2545.

Thoenen, H., 1995. Neurotrophins and neuronal plasticity. Science 270, 593-598.

Tully, T., 1997. Regulation of gene expression and its role in long-term memory and synaptic plasticity. Proc. Natl. Acad. Sci. USA 94, 4239-4241.

Walton, M., Connor, B., Lawlor, P., Young, D., Sirimanne, E., Gluckman, P., Cole, G., Dragunow, M., 1999. Neuronal death and survival in two models of hypoxic-ischemic brain damage. Brain Res. Brain Res. Rev. 29, 137-168.

Wickelgren, I., 1998. Tracking insulin to the mind. Science 280, 517-519.

Yin, J.C., Tully, T., 1996. CREB and the formation of long-term memory. Curr. Opin. Neurobiol. 6, $264-268$.

Yirmiya, R., Tio, D.L., Taylor, A.N., 1996. Effects of fetal alcohol exposure on fever, sickness behavior, and pituitary-adrenal activation induced by interleukin-1b in young adult rats. Brain Behav. Immun. 10, 205-220.

Zhao, W., Chen, H., Xu, H., Moore, E., Meiri, N., Quon, M.J., Alkon, D.L., 1999. Brain insulin receptors and spatial memory. Correlated changes in gene expression, tyrosine phosphorylation, and signaling molecules in the hippocampus of water maze trained rats. J. Biol. Chem. $274,34893-34902$. 